\title{
Laparoscopy in Acute Care Surgery: Repair of Perforated Duodenal Ulcer
}

\author{
Mohammad H. Jamal ${ }^{a}$ Abdulazeez Karam ${ }^{b}$ Nourah Alsharqawi ${ }^{\text {b }}$ \\ Abdulla Buhamra $^{a}$ Ibtesam AlBader ${ }^{a}$ Jasem Al-Abbad ${ }^{a}$ Mohammad Dashti $^{a}$ \\ Yaser B. Abulhasan ${ }^{a}$ Husain Almahmeed $^{\mathrm{b}}$ Salman AlSabah ${ }^{\mathrm{a}}$ \\ ${ }^{a}$ Department of Surgery, Kuwait University, Kuwait City, Kuwait; ${ }^{b}$ Department of Surgery, McGill University Health \\ Center, McGill University, Montreal, QC, Canada
}

\section{Significance of the Study}

- This study shows the effectiveness and safety of the use of laparoscopy as a first approach to treat duodenal perforation. It also shows better outcomes in laparoscopically treated patients in terms of fewer admissions to intensive care, fewer acute kidney injuries, and less acute respiratory distress syndrome in the laparoscopic group.

\section{Keywords}

Acute care surgery · Peptic ulcer disease - Duodenal perforation · Foregut

\begin{abstract}
Introduction: The use of laparoscopic management as a first choice for the treatment of duodenal perforation is gaining ground but is not routine in many centers. In this report, we aim to report our experience with laparoscopy as the first approach for the repair of duodenal perforation. Materials and Methods: This is a retrospective review of patients during our initial experience with the use of laparoscopy for the treatment of duodenal perforation between 2009 and 2013. Results: A total of 100 patients underwent management of duodenal perforation. Laparoscopy was attempted initially in 76 patients (76\%) and completed in 64 patients (64\%). The length of hospital stay was shorter in the laparoscopic group (mean 2.6) than in the open group (mean 3.1) $(p=0.008)$. Complications developed in 14 patients (20\%). There was a
\end{abstract}

tendency towards fewer admissions to intensive care, less acute kidney injuries, and less acute respiratory distress syndrome in the laparoscopic group. In patients who underwent laparoscopic surgery, the chances of uneventful recovery were 4.3 times higher than in those patients who underwent open surgery $(95 \% \mathrm{Cl} 1.3-13.5, p=0.014)$. Conclusions: Laparoscopy in the treatment of perforated duodenal ulcer is safe and can be utilized as a routine approach for the treatment of this pathology.

(c) 2019 The Author(s) Published by S. Karger AG, Basel

\section{Introduction}

Perforated peptic ulcer disease is a surgical emergency that has seen major changes in its management over the last few decades. The discovery of Helicobacter pylori and its relationship with the causality of peptic ulcer, the development of proton pump inhibitors, and the use of laparos-

\begin{tabular}{ll}
\hline KARGER & $\begin{array}{l}\text { ( } 2019 \text { The Author(s) } \\
\text { Published by S. Karger AG, Basel }\end{array}$ \\
E-Mail karger@karger.com & $\begin{array}{l}\text { This is an Open Access article licensed under the Creative Commons } \\
\text { Attribution-NonCommercial-4.0 International License (CC BY-NC) } \\
\text { (http://www.karger.com/Services/OpenAccessicense), applicable to } \\
\text { the online version of the article only. Usage and distribution for com- } \\
\text { mww.karger.com/mpp }\end{array}$ \\
&
\end{tabular}

Mohammad H. Jamal

Department of Surgery, Kuwait University PO Box 24923

Kuwait City (Kuwait)

E-Mail Mohammad.jamal@ mail.mcgill.ca 
copy along with endoscopy have contributed greatly to new management algorithms for peptic ulcer disease. Despite these advances, the rates of ulcer perforation needing surgery have not declined as much as the global incidence of peptic ulcer disease has; therefore, emergent surgery is still performed widely for the treatment of complications of peptic ulcer disease [1]. The surgical strategies that started with the simple suture of perforation progressed to the addition of gastric resections, truncal vagotomy, and highly selective vagotomy only to go back to the closure of the perforation without the need for acid reduction procedures due to the discovery of proton pump inhibitors and the treatment for $H$. pylori infection. This, along with the introduction of laparoscopy, allowed the use of more minimally invasive techniques for the treatment of complications of peptic ulcer disease given the simpler procedure needed.

The use of laparoscopy in emergency surgery carries many theoretical advantages, including minimal access for diagnostic purposes with high sensitivity and specificity in those emergency situations which can pose diagnostic challenges. In the beginning of the laparoscopic era, there was some debate concerning the use of insufflation during laparoscopy in emergency surgery, with suggestions that carbon dioxide $\left(\mathrm{CO}_{2}\right)$ insufflation may increase bacteremia, endotoxemia, and unfavorable hemodynamic changes in patients with peritonitis [2]. However, several studies reported outcomes as good as for open surgery when using laparoscopy for the treatment of surgical peritonitis [3-5].

Some surgeons still prefer the use of open surgery for patients with abdominal emergencies citing the need for a damage control strategy to improve the outcome of those cohorts of sick patients. The use of laparoscopy is thought to prolong the procedure time, and this may lead to detrimental effects on perforated peptic ulcer patients who are septic with variable states of shock. The laparoscopic skills, techniques, and instruments have improved greatly since the dawn of laparoscopy in the last decade of the last century, which contributed to a shorter operative time and a new breed of surgeons who have laparoscopic skills equivalent to the open operative skills of previous generations of surgeons. In this study, we retrospectively review our experience with management of perforated duodenal ulcer (PDU) in our center where laparoscopic repair is the preferred management option.

\section{Methods}

After obtaining Institutional Review Board approval, we performed this retrospective review of all patients who were diagnosed with duodenal perforation and who underwent repair of duodenal perforation between January 2009 and December 2013 at 2 major hospitals in Kuwait, Mubarak, and Amiri hospitals. Data, including patient demographics, diagnostic methods, management, and outcomes, were evaluated by chart review. All patients were treated surgically and had their diagnoses confirmed at the time of surgery.

\section{Peri-Operative Management}

All patients who had peritoneal signs with air under the diaphragm on an erect chest X-ray were offered a diagnostic laparoscopy or exploratory laparotomy. Computed tomography of the abdomen was performed in those who did not have air under the diaphragm on erect chest X-rays, and if signs of perforation were encountered (air outside the bowel, free fluid, and thickened bowel), the patients were taken for a diagnostic laparoscopy or exploratory laparotomy. The decision of whether to perform a laparotomy or laparoscopy was left to the treating surgeon. Patients were started on intravenous proton pump inhibitor therapy and intravenous antibiotics along with nasogastric (NG) decompression once the diagnosis of a PDU was suspected.

All surgeries were performed by the on-call team and led by a surgeon who had completed their residency training. During surgery, conversion from laparoscopy to laparotomy was done mostly if the site of perforation was not clearly identified or if the perforation was large. All patients had drains inserted at the time of surgery. Leak test was not performed routinely. Postoperatively, patients were continued on NG decompression until the drain output was minimal and serosanguinous. Once that was observed, the NG was removed and the patient was allowed to have clear fluids and then progressed according to response along with drain removal. All patients were treated with $H$. pylori eradication therapy. Patients were discharged once they started tolerating diet with no signs of sepsis or abdominal pain.

\section{Surgical Technique}

For laparoscopy, the patients were placed supine on the operating table with arms out. An open technique was used to get into the abdomen and place the first $10-\mathrm{mm}$ port in the midline in the periumbilical region. A $30^{\circ}$ camera was used to inspect the abdomen. The operating surgeon stood in-between the patient's legs, and a $5-\mathrm{mm}$ port was inserted in the left upper quadrant in the midclavicular region a hand breadth below the costal margin. Another $5-\mathrm{mm}$ port was inserted in the midclavicular line in the right upper quadrant a hand breadth below the costal margin. If retraction was needed, a $5-\mathrm{mm}$ port was inserted in the right upper quadrant in the anterior axillary line and used to grasp the gallbladder towards the tip of the right shoulder. Once the perforation was identified, a piece of the omentum was sutured to the perforation site using 2.00-3.00 Vicryl sutures. If the perforation site was not clearly identified, intraoperative endoscopy was performed. Leak test was not routinely performed. The abdomen was washed copiously in all patients with 4,000-6,000 mL normal saline until the abdominal cavity was clean. All patients had drains inserted. The $10-\mathrm{mm}$ port fascia was closed in all patients with a Vicryl 0 suture. The drains were removed once the patient tolerated a normal diet with nonbilious output of the drain. In the event of an open approach or of conversion, a midline laparotomy was performed and the procedure was carried out similarly. All patients had a gastroscopy done within 6-8 weeks after surgery to identify $H$. pylori status. 
Table 1. Demographic and clinical features of the patients $(n=100)$

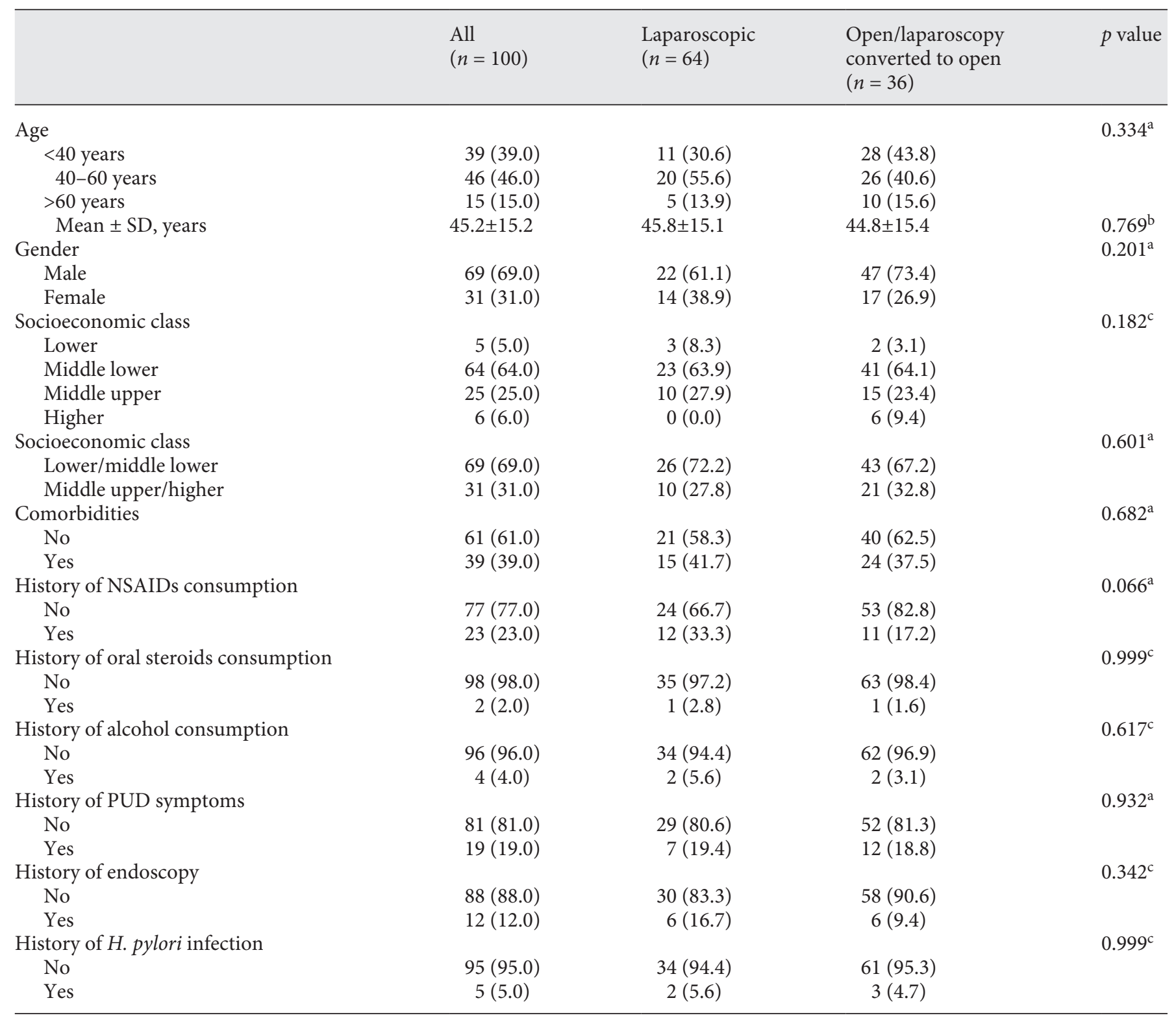

Values are presented as $n(\%)$. NSAIDs, nonsteroidal anti-inflammatory drugs; PUD, peptic ulcer disease. $p$ values were generated using ${ }^{\mathrm{a}}$ Pearson $\chi^{2}$ test, ${ }^{\mathrm{b}}$ independent $t$ test, and ${ }^{\mathrm{c}}$ Fisher's exact test.

\section{Results}

During the study period, 108 patients underwent emergency surgery for PDU. Eight patients were excluded due to missing clinical information. The demographic and clinical features of the patients are summarized in Table 1. Seventy-six patients underwent laparoscopic repair initially, while 24 underwent open surgical repair. Of the 76 patients who underwent laparoscopic attempt at repair, the repair was completed laparoscopically in 64 patients $(84 \%)$. The mean age of the patients who underwent laparoscopic repair was $45.8(\mathrm{SD} \pm 15.1)$ years and for the open repair $44.8(\mathrm{SD} \pm 15.4)$ years.

A majority of the cases $(n=78)$ presented with pain, in whom $>70 \%$ had epigastric pain. Only 12 patients presented with a symptom duration of more than $24 \mathrm{~h}$, while 88 patients presented with a symptom duration of less than $24 \mathrm{~h}$. Five patients had hemoptysis at the time of pre- 
Table 2. Clinical data of the patients on admission $(n=100)$

\begin{tabular}{|c|c|c|c|c|}
\hline & $\begin{array}{l}\text { All } \\
(n=100)\end{array}$ & $\begin{array}{l}\text { Laparoscopic } \\
(n=64)\end{array}$ & $\begin{array}{l}\text { Open/laparoscopy } \\
\text { converted to open } \\
(n=36)\end{array}$ & $p$ value \\
\hline Pain site & & & & $0.880^{\mathrm{a}}$ \\
\hline Epigastric & $62(62.0)$ & $23(63.9)$ & $39(60.9)$ & \\
\hline Generalized & $33(33.0)$ & $12(33.3)$ & $21(32.8)$ & \\
\hline Other sites & $5(5.0)$ & $1(2.8)$ & $4(6.3)$ & \\
\hline Time since onset of pain & & & & $0.342^{\mathrm{a}}$ \\
\hline$<24 \mathrm{~h}$ & $88(88.0)$ & $30(83.3)$ & $58(90.6)$ & \\
\hline$\geq 24 \mathrm{~h}$ & $12(12.0)$ & $6(16.7)$ & $6(9.4)$ & \\
\hline Nausea and vomiting & & & & $0.285^{\mathrm{b}}$ \\
\hline No & $27(27.0)$ & $12(33.3)$ & $15(23.4)$ & \\
\hline Yes & $73(73.0)$ & $24(66.7)$ & $49(76.6)$ & \\
\hline Hemoptysis & & & & $0.651^{\mathrm{a}}$ \\
\hline No & $95(95.0)$ & $35(97.2)$ & $60(93.8)$ & \\
\hline Yes & $5(5.0)$ & $2(2.8)$ & $4(6.2)$ & \\
\hline Guarding & & & & $0.656^{\mathrm{b}}$ \\
\hline No & $19(19.0)$ & $6(16.7)$ & $13(20.3)$ & \\
\hline Yes & $81(81.0)$ & $30(83.3)$ & $51(79.7)$ & \\
\hline Shock & & & & $0.016^{\mathrm{a}}$ \\
\hline No & $89(89.0)$ & $28(77.8)$ & $61(95.3)$ & \\
\hline Yes & $10(10.0)$ & $8(22.2)$ & $3(4.7)$ & \\
\hline Diagnosis made by & & & & $0.793^{\mathrm{b}}$ \\
\hline Erect chest X-ray & $35(35.0)$ & $12(33.3)$ & $23(35.9)$ & \\
\hline $\mathrm{CT}$ & $65(65.0)$ & $24(66.7)$ & $41(64.1)$ & \\
\hline ASA classification & & & & $0.002^{\mathrm{a}}$ \\
\hline 1 & $65(65.0)$ & $23(63.9)$ & $42(65.6)$ & \\
\hline 2 & $29(29.0)$ & $7(19.4)$ & $22(34.4)$ & \\
\hline 3 & $6(6.0)$ & $6(16.7)$ & $0(0.0)$ & \\
\hline Boey score & & & & $0.012^{\mathrm{a}}$ \\
\hline 0 & $79(79.0)$ & $24(66.7)$ & $55(85.9)$ & \\
\hline 1 & $16(16.0)$ & $7(19.4)$ & $9(14.1)$ & \\
\hline 2 & $3(3.0)$ & $3(8.3)$ & $0(0.0)$ & \\
\hline 3 & $2(2.0)$ & $2(5.6)$ & $0(0.0)$ & \\
\hline
\end{tabular}

Values are presented as $n(\%)$. CT, computed tomography; ASA, American Society of Anesthesiologists. $p$ values were generated using ${ }^{\text {a }}$ Fisher's exact test and ${ }^{\mathrm{b}}$ Pearson $\chi^{2}$ test.

sentation and 10 patients had shock. Table 2 summarizes the clinical data of patients at the time of admission.

Of the patients operated laparoscopically, $12(16 \%)$ were converted to open repair mostly due to the inability to identify the site of perforation or due to difficult exposure laparoscopically. Eighty-four patients had Graham patch repair, while 13 only had primary suture repair. One patient had wide drainage only. The outcomes when comparing the open and the laparoscopic groups are summarized in Table 3.

The results of the multivariate stepwise logistic regression analyses with uneventful recovery as an outcome variable are summarized in Table 4 . Comorbidi- ties, Boey score, and type of surgery were the factors independently associated with uneventful recovery. The chances of uneventful recovery among patients who did not have any comorbidities were 4.2 times higher than those of patients with any comorbidities (95\% CI 1.3$13.3, p=0.015$ ). Also, compared to patients whose Boey score was zero, the chances of uneventful recovery among those with a Boey score $\geq 1$ were 3.7 times higher (95\% CI 1.1-12.6, $p=0.036)$. Among patients who underwent laparoscopic surgery, the chances of uneventful recovery were 4.3 times higher than in those patients who underwent open surgery (95\% CI 1.3-13.5, $p=0.014)$. 
Table 3. Comparison of outcomes between the open and laparoscopic repairs

\begin{tabular}{llll}
\hline Outcomes & Laparoscopic & $\begin{array}{l}\text { Open/laparoscopy } \\
\text { converted to open }\end{array}$ & $p$ value \\
\hline ICU admission & $7(9.2 \%)$ & $6(27.3 \%)$ & 0.067 \\
ARDS & $3(3.9 \%)$ & $4(18.2 \%)$ & 0.043 \\
DVT/pulmonary embolism & $1(1.3 \%)$ & $0(0.0 \%)$ & 1.0000 \\
Acute kidney injury & $2(2.6 \%)$ & $5(22.7 \%)$ & 0.006 \\
30-day mortality & $0(0.0 \%)$ & $1(4.5 \%)$ & 0.224 \\
\hline
\end{tabular}

ICU, intensive care unit; ARDS, acute respiratory distress syndrome; DVT, deep venous thrombosis.

\section{Discussion}

In this retrospective review of a contemporary cohort of patients presenting with duodenal perforation at a center that uses laparoscopy as the preferred method of management, we found better outcomes when a laparoscopic approach to surgery was used as compared to an open approach. There were fewer acute kidney injuries and less acute respiratory distress syndrome among patients who underwent laparoscopic repair of their PDU when compared to patients who had open surgery. There was also a tendency for fewer admissions to intensive care.

A recent study by Teoh et al. [6] looked at 373 patients who presented over a 10 -year period with PDU at a center that adopts a laparoscopy-first approach. They found that a laparoscopic approach in high-risk patients was not associated with increased morbidity and mortality when compared to an open approach, particularly if the American Society of Anesthesiologists (ASA) grading was below 3. A Cochrane meta-analysis [7] including 3 randomized controlled trials compared open to laparoscopic surgery for the management of perforated peptic ulcer disease and found a trend for reduced intra-abdominal septic complications, wound infections, postoperative ileus, pulmonary complications, and mortality in the laparoscopic group. An earlier meta-analysis by Lau [8] found a lower incidence of wound infections in the laparoscopic group and lower requirement for analgesia but a higher rate of reoperation. In our contemporary cohort of patients, no reoperation was needed in the 2 groups. We started performing laparoscopic surgery for the management of PDU in the year 2003, but selected this cohort to highlight the results of laparoscopic repair after developing enough expertise among the surgeons with its use along with the use of the most recent technologies. Laparoscopic instruments and cameras have undergone major
Table 4. Significant factors independently associated with uneventful recovery using stepwise multiple logistic regression analyses

\begin{tabular}{lll}
\hline & Private AOR (95\% CI) & $p$ value \\
\hline $\begin{array}{l}\text { Comorbidities } \\
\quad \text { Yes }\end{array}$ & 1.00 & \\
$\quad$ No & $4.19(1.32-13.31)$ & 0.015 \\
$\begin{array}{l}\text { Boey score } \\
\quad\end{array}$ & 1.00 & \\
$\geq 1$ & $3.72(1.09-12.66)$ & 0.036 \\
Type of surgery & 1.00 & \\
$\quad$ Open & $4.25(1.34-13.53)$ & 0.014 \\
$\quad$ Laparoscopic & \multicolumn{2}{l}{} \\
\hline \multicolumn{2}{l}{ AOR, adjusted odds ratio; CI, confidence interval. } \\
\hline
\end{tabular}

improvements over the last decade contributing to better visualization and ease of the operation.

PDU is associated with sepsis, septic shock, morbidity, and possible mortality; therefore, prompt management is required once it is identified. Predicting outcome in these patients may help in selecting the most appropriate management strategy. The Boey score is the most widely used score to predict mortality in PDU [9]. The score is simple and is calculated based on 3 factors: the presence of major medical illness, presence of shock on admission, and duration of perforation of more than $24 \mathrm{~h}$. In the original paper describing the score, all those with a score of 3 had a $100 \%$ mortality. In our study, we had 1 mortality in a patient who had a Boey score of 3 . Having a score that predicts a worse outcome might help in stratifying patients and selecting them for different management groups. Our study does not directly address these questions, but does a high-risk patient require a minimal approach to avoid wound infection, increased inflammation and pain, which are associated with open surgery? Or is it that a high-risk patient is better 
treated with the procedure associated with the shortest operative time? The answers to these questions are essential in guiding management, especially with the invention of endoscopic methods for the treatment of PDU. Three randomized controlled trials included in a Cochrane metaanalysis showed varying results in terms of comparison of operative time between open and laparoscopic surgery [7]. One study published in 1996 showed a statistically significantly shorter operative time in open surgery [10], while a study published in 2002 showed the opposite; laparoscopic surgery had a significantly shorter operative time [11]. The third study showed a shorter open surgery time, but this was not statistically significant [12]. A more recent metaanalysis by Cirocchi et al. [13] reviewed 8 randomized controlled trials comparing open to laparoscopic repair of peptic ulcer perforation and found a significant advantage of laparoscopic repair only for postoperative pain in the first $24 \mathrm{~h}$ and for postoperative wound infection.

With regard to the type of repair performed, most of the patients in our study underwent Graham patch repair (87\%), and $13 \%$ underwent simple closure only. A recent randomized controlled trial showed no difference in terms of complications and bile leakage between simple closure and Graham patch repair [14]. Sutureless repair with gelatin sponge and fibrin glue was explored in the past, and Lau et al. [10], in a randomized controlled trial, showed the same results in terms of recovery and complications in the sutureless group of patients when compared to patients who had Graham patch repair. Advances in endoscopic techniques allowed attempting a closure of PDU with stents. Bergström et al. [15] reported on 8 patients who had self-expandable metal stents and drain insertion for PDU and showed good recovery in all patients with only 1 mortality due to late diagnosis. Three of these patients had the stent inserted under sedation in the intensive care unit avoiding general anesthesia. Future randomized studies should compare various mini- mally invasive techniques, including stenting, to determine their role in various management protocols. Other innovative approaches to the management of PDU include natural orifice transluminal endoscopic surgery (NOTES). Bingener et al. [16] described the performance of a hybrid NOTES/laparoscopy for the management of PDU, in which the endoscope was passed through the perforation and used to grasp a piece of omentum or falciform ligament before clipping it endoscopically to the site of perforation.

This study is a retrospective review with all the bias associated with such a study design. However, it is focused on a contemporary group of patients within a relatively short period of time, to highlight the outcomes of laparoscopic and open surgical management of PDU in an era characterized by surgeons skilled in laparoscopy using advanced laparoscopic techniques and instruments.

\section{Conclusion}

The use of laparoscopy in acute care surgery particularly for the treatment of perforated PDU is safe and associated with better outcomes even in patients with higher comorbidities.

\section{Statement of Ethics}

Ethical approval for conducting the study was obtained from Kuwait University Ethical Committee and Kuwait Ministry of Health.

\section{Disclosure Statement}

The authors have no conflicts of interest to declare.

\section{References}

1 Søreide K, Thorsen K, Søreide JA. Strategies to improve the outcome of emergency surgery for perforated peptic ulcer. Br J Surg. 2014 Jan;101(1):e51-64.

2 Bergamaschi R, Mårvik R, Johnsen G, Thoresen JE, Ystgaard B, Myrvold HE. Open vs laparoscopic repair of perforated peptic ulcer. Surg Endosc. 1999 Jul;13(7):679-82.

3 Bailey IS, Rhodes M, O’Rourke N, Nathanson L, Fielding G. Laparoscopic management of acute small bowel obstruction. Br J Surg. 1998 Jan;85(1):84-7.
4 Druart ML, Van Hee R, Etienne J, Cadière GB, Gigot JF, Legrand M, et al. Laparoscopic repair of perforated duodenal ulcer. A prospective multicenter clinical trial. Surg Endosc. 1997 Oct;11(10):1017-20.

5 Siu WT, Chau CH, Law BK, Tang CN, Ha PY, Li MK. Routine use of laparoscopic repair for perforated peptic ulcer. Br J Surg. 2004 Apr; 91(4):481-4.
6 Teoh AY, Chiu PW, Kok AS, Wong SK, Ng $\mathrm{EK}$. The selective use of laparoscopic repair is safe in high-risk patients suffering from perforated peptic ulcer. World J Surg. 2015 Mar; 39(3):740-5.

7 Sanabria A, Villegas MI, Morales Uribe CH. Laparoscopic repair for perforated peptic ulcer disease. Cochrane Database Syst Rev. 2013 Feb;(2):CD004778.

8 Lau H. Laparoscopic repair of perforated peptic ulcer: a meta-analysis. Surg Endosc. 2004 Jul;18(7):1013-21. 
9 Boey J, Choi SK, Poon A, Alagaratnam TT. Risk stratification in perforated duodenal ulcers. A prospective validation of predictive factors. Ann Surg. 1987 Jan;205(1):22-6.

10 Lau WY, Leung KL, Kwong KH, Davey IC, Robertson C, Dawson JJ, et al. A randomized study comparing laparoscopic versus open repair of perforated peptic ulcer using suture or sutureless technique. Ann Surg. 1996 Aug; 224(2):131-8

11 Siu WT, Leong HT, Law BK, Chau CH, Li AC, Fung KH, et al. Laparoscopic repair for perforated peptic ulcer: a randomized controlled trial. Ann Surg. 2002 Mar;235(3):313-9.
12 Bertleff MJ, Halm JA, Bemelman WA, van der Ham AC, van der Harst E, Oei HI, et al. Randomized clinical trial of laparoscopic versus open repair of the perforated peptic ulcer: the LAMA Trial. World J Surg. 2009 Jul;33(7): 1368-73.

13 Cirocchi R, Soreide K, Di Saverio S, Rossi E, Arezzo A, Zago M, et al. Meta-analysis of perioperative outcomes of acute laparoscopic versus open repair of perforated gastroduodenal ulcers. J Trauma Acute Care Surg. 2018 Aug; 85(2):417-25

14 Bhandari V, Gunasekaran G, Naik D, Paruthy SB, Choudhry L, Garg P. A comparative study between figure of eight suturing technique and omentopexy in closure of peptic ulcer perforation: a prospective study on $60 \mathrm{pa}-$ tients with APACHE II score $\leq 10$. Int Surg J. 2015;2(1):31-7.

15 Bergström M, Arroyo Vázquez JA, Park PO. Self-expandable metal stents as a new treatment option for perforated duodenal ulcer. Endoscopy. 2013;45(3):222-5.

16 Bingener J, Loomis EA, Gostout CJ, Zielinski MD, Buttar NS, Song LM, et al. Feasibility of NOTES omental plug repair of perforated peptic ulcers: results from a clinical pilot trial. Surg Endosc. 2013 Jun;27(6):2201-8. 